\title{
Multimodal Abduction External Semiotic Anchors and Hybrid Representations
}

\author{
LORENZO MAGNANI, Department of Philosophy and Computational \\ Philosophy Laboratory. University of Pavia. Pavia (Italy). Also \\ Department of Philosophy. Sun Yat-sen University. Guangzhou \\ (P.R.China). \\ Email: lmagnani@unipv.it
}

\begin{abstract}
Our brains make up a series of signs and are engaged in making or manifesting or reacting to a series of signs: through this semiotic activity they are at the same time engaged in "being minds" and so in thinking intelligently. An important effect of this semiotic activity of brains is a continuous process of "externalization of the mind" that exhibits a new cognitive perspective on the mechanisms underling the semiotic emergence of abductive processes of meaning formation. To illustrate this process I will take advantage of the analysis of some aspects of the cognitive interplay between internal and external representations. I consider this interplay critical in analyzing the relation between meaningful semiotic internal resources and devices and their dynamical interactions with the externalized semiotic materiality suitably stocked in the environment. Hence, minds are material, "extended" and artificial in themselves. A considerable part of human abductive thinking is occurring through an activity consisting in a kind of reification in the external environment (that originates what I call semiotic anchors) and a subsequent re-projection and reinterpretation through new configurations of neural networks and chemical processes. I also illustrate how this activity takes advantage of hybrid representations and how it can nicely account for various processes of creative and selective abduction, bringing up the question of how multimodal aspects involving a full range of sensory modalities are important in hypothetical reasoning.
\end{abstract}

Keywords: abduction, semiotics, external and internal representations, distributed cognition.

\section{The Centrality of Abduction}

If we decide to increase knowledge on both cognitive and semiotic aspects of hypothetical thinking it is necessary to develop a cognitive model of creativity able to represent not only "novelty" and "unconventionality", but also some features commonly referred to as the entire creative process, such as the hybrid modeling activity developed in the interplay between internal and external representations. The philosophical concept of abduction may be a candidate to solve this problem, and offers an approach to model creative processes of meaning generation in a completely explicit and formal way, which can fruitfully integrate the narrowness proper of a merely psychological approach, too experimentally human-oriented.

A hundred years ago, C. S. Peirce [52] coined the concept of abduction in order to illustrate that the process of scientific discovery is not irrational and that a methodology of discovery is possible. Peirce interpreted abduction essentially as an "inferential" creative process of generating a new hypothesis. Abduction has a logical 


\section{Multimodal Abduction}

form - fallacious, if we model abduction by using classical syllogistic logic - distinct from deduction and induction. Reasoning which starts from reasons and looks for consequences is called deduction; that which starts from consequences and looks for reasons is called abduction.

Abduction - a distinct form of reasoning - is the process of inferring certain facts and/or laws and hypotheses that render some sentences plausible, that explain or discover some (eventually new) phenomenon or observation; it is the process of reasoning in which explanatory hypotheses are formed and evaluated. There are two main epistemological meanings of the word abduction [35]: 1) abduction that only generates "plausible" hypotheses ("selective" or "creative") and 2) abduction considered as inference "to the best explanation", which also evaluates hypotheses (cf. Figure 1). An illustration from the field of medical knowledge is represented by the discovery of a new disease and the manifestations it causes which can be considered as the result of a creative abductive inference. Therefore, "creative" abduction deals with the whole field of the growth of scientific knowledge. This is irrelevant in medical diagnosis where instead the task is to "select" from an encyclopedia of pre-stored diagnostic entities. We can call both inferences ampliative, selective and creative, because in both cases the reasoning involved amplifies, or goes beyond, the information incorporated in the premises.

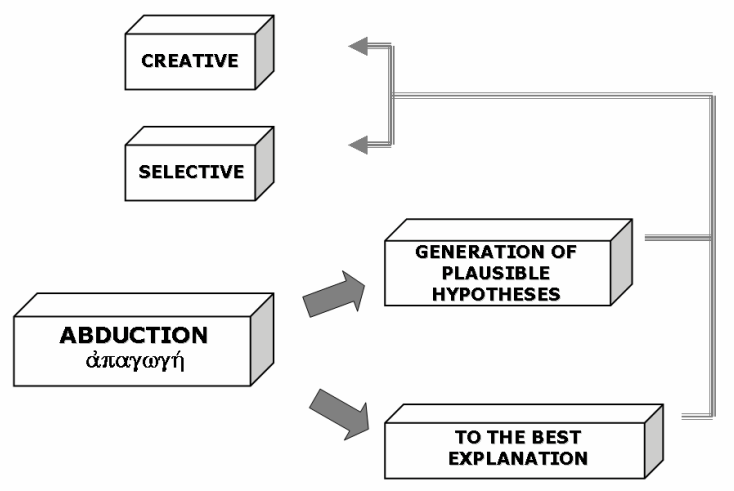

FIG. 1. Creative and selective abduction.

I have introduced [35] the concept of theoretical abduction as a form of neural and basically internal processing. I maintain that there are two kinds of theoretical abduction, "sentential", related to logic and to verbal/symbolic inferences, and "model-based", related to the exploitation of models such as diagrams, pictures, etc, cf. below in this paper, section 1.3 and subsection 3 (cf. Figure 2).

Theoretical abduction certainly illustrates much of what is important in creative abductive reasoning, in humans and in computational programs, but fails to account for many cases of explanations occurring in science when the exploitation of environment is crucial. It fails to account for those cases in which there is a kind of "discovering through doing", cases in which new and still unexpressed information 


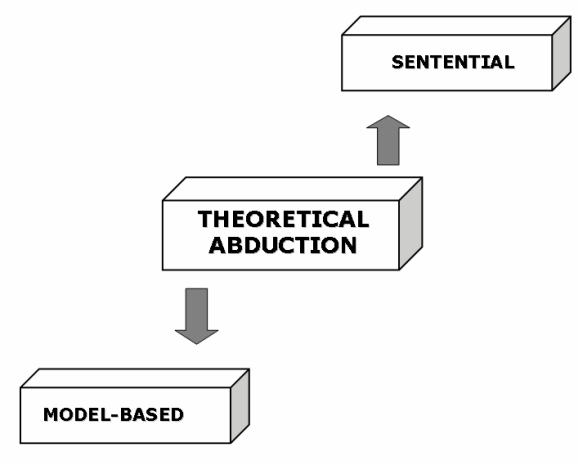

FIG. 2. Theoretical abduction.

is codified by means of manipulations of some external objects I have called epistemic mediators [35]. The concept of manipulative abduction ${ }^{1}$ captures a large part of scientific thinking where the role of action is central, and where the features of this action are implicit and hard to be elicited: action can provide otherwise unavailable information that enables the agent to solve problems by starting and by performing a suitable abductive process of generation or selection of hypotheses.

In section $4 \mathrm{I}$ will describe how manipulative abduction can nicely account for the relationship between meaningful behavior and dynamical interactions with the environment. The following sections illustrate that at the roots of the creation of new meanings there is a process of externalization that exhibits a new cognitive description of the mechanisms underling the emergence of meaning processes through semiotic delegations to the environment.

\subsection{The "Internal" Side of Creative Reasoning}

Throughout his career Peirce defended the thesis that, besides deduction and induc$\operatorname{tion}^{2}$, there is a third mode of inference that constitutes the only method for really improving scientific knowledge, which he called abduction. Science improves and grows continuously, but this continuous enrichment cannot be due to deduction, nor to induction: deduction does not produce any new idea, whereas induction produces very simple ideas. New ideas in science are due to abduction, a particular kind of non-deductive ${ }^{3}$ inference that involves the generation and evaluation of explanatory hypotheses.

I and others [61] have developed an epistemological model of medical reasoning, called the Select and Test Model (ST-MODEL) which can be described in terms of the

\footnotetext{
${ }^{1}$ Manipulative abduction and epistemic mediators are introduced and illustrated in [37] and [35]

${ }^{2}$ Peirce clearly contrasted abduction with induction and deduction, by using the famous syllogistic model. More details on the differences between abductive and inductive/deductive inferences can be found in [15] and [35].

${ }^{3}$ Non-deductive if we use the attribute "deductive" as designated by classical logic.
} 


\section{Multimodal Abduction}

classical notions of abduction, deduction and induction. It describes the different roles played by such basic inference types in developing various kinds of medical reasoning (diagnosis, therapy planning, monitoring) but can be extended and regarded also as an illustration of scientific theory change. The model is consistent with the Peircian view regarding the various stages of scientific inquiry in terms of "hypothesis" generation, deduction (prediction), and induction.

As previously illustrated, I have introduced a distinction between "creative" and "selective" abduction. All we can expect of our "selective" abduction, is that it tends to produce hypotheses for further examination that have some chance of turning out to be the best explanation. Selective abduction will always produce hypotheses that give at least a partial explanation and therefore have a small amount of initial plausibility. In the syllogistic view advocated by Peirce (see below) concerning abduction as inference to the best explanation one might require that the final chosen explanation be the most "plausible".

Since the time of John Stuart Mill, the name given to all kinds of non deductive reasoning has been induction, considered as an aggregate of many methods for discovering causal relationships. Consequently induction in its widest sense is an ampliative process of the generalization of knowledge. Peirce distinguished various types of induction: a common feature of all kinds of induction is the ability to compare individual statements: by using induction it is possible to synthesize individual statements into general laws - inductive generalizations - in a defeasible way, but it is also possible to confirm or discount hypotheses.

Following Peirce, I am clearly referring here to the latter type of induction: abduction creates or selects hypotheses; from these hypotheses consequences are derived by deduction that are compared with the available data by induction. This perspective on hypothesis testing in terms of induction is also known in philosophy of science as the "hypothetico-deductive method" [19] and is related to the idea of confirmation of scientific hypotheses, predominant in neopositivistic philosophy but also present in the anti-inductivist tradition of falsificationism [59].

Deduction is an inference that refers to a logical implication. Deduction may be distinguished from abduction and induction on the grounds that the truth of the conclusion of the inference is guaranteed by the truth of the premises on which it is based only in deduction. Deduction refers to the so-called non-defeasible arguments. It should be clear that, on the contrary, when we say that the premises of an argument provide partial support for the conclusion, we mean that if the premises were true, they would give us good reasons - but not conclusive reasons - to accept the conclusion. That is to say, although the premises, if true, provide some evidence to support the conclusion, the conclusion may still be false (arguments of this type are called inductive, or abductive, arguments).

All these distinctions need to be exemplified. To describe how the three inferences operate, it is useful to start with a very simple example dealing with diagnostic reasoning and illustrated (as Peirce initially did), in syllogistic terms:

1. If a patient is affected by a pneumonia, his/her level of white blood cells is increased.

2. John is affected by a pneumonia.

3. John's level of white blood cells is increased. 
(This syllogism is known as Barbara).

By deduction we can infer (3) from (1) and (2). Two other syllogisms can be obtained from Barbara if we exchange the conclusion (or Result, in Peircian terms) with either the major premise (the Rule) or the minor premise (the Case): by induction we can go from a finite set of facts, like (2) and (3), to a universally quantified generalization - also called categorical inductive generalization, like the piece of hematologic knowledge represented by (1) (in this case we meet induction as the ability to generate simple laws, contrasted with induction as a way to confirm or discard hypotheses, cf. above). Starting from knowing - selecting - (1) and "observing" (3) we can infer (2) by performing a selective abduction. The abductive inference rule corresponds to the well-known fallacy called affirming the consequent (simplified to the propositional case)

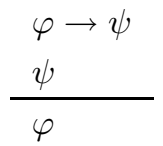

It is useful to give another example, describing an inference very similar to the previous one:

1. If a patient is affected by a beta-thalassemia, his/her level of hemoglobin A2 is increased.

2. John is affected by a beta-thalassemia.

3. John's level of hemoglobin A2 is increased.

Such an inference is valid, that is not affected by uncertainty, since the manifestation (3) is pathognomonic for beta-thalassemia (as expressed by the biconditional in $\varphi \leftrightarrow \psi)$. This is a special case, where there is no abduction because there is no "selection", in general clinicians very often have to deal with manifestations which can be explained by different diagnostic hypotheses: in this case the inference rule corresponds to

$$
\begin{aligned}
& \varphi \leftrightarrow \psi \\
& \psi \\
& \hline \varphi
\end{aligned}
$$

\subsection{Sentential Abduction}

Many attempts have been made to model abduction by developing some formal tools in order to illustrate its computational properties and the relationships with the different forms of deductive reasoning [see, for example, [8]. Some of the formal models of abductive reasoning are based on the theory of the epistemic state of an agent [4], where the epistemic state of an individual is modeled as a consistent set of beliefs that can change by expansion and contraction (belief revision framework).

Deductive models of abduction may be characterized as follows. An explanation for $\beta$ relative to background theory $T$ will be any $\alpha$ that, together with $T$, entails $\beta$ (normally with the additional condition that $\alpha \cup T$ be consistent). Such theories are usually generalized in many directions: first of all by showing that explanations 


\section{Multimodal Abduction}

entail their conclusions only in a defeasible way (there are many potential explanations), thus joining the whole area of so-called nonmonotonic logic or of probabilistic treatments; second, trying to show how some of the explanations are relatively implausible, elaborating suitable technical tools (for example in terms of modal logic) able to capture the notion of preference among explanations.

The idea of consistency that underlies some of the more recent deductive consistencybased models of selective abduction (diagnostic reasoning) is the following: any inconsistency (anomalous observation) refers to an aberrant behavior that can usually be accounted for by finding some set of components of a system that, if behaving abnormally, will entail or justify the actual observation. The observation is anomalous because it contradicts the expectation that the system involved is working according to specification. This types of deductive model go beyond the mere treatment of selective abduction in terms of preferred explanations and include the role of those components whose abnormality makes the observation (no longer anomalous) consistent with the description of the system $[4,36]$.

This kind of sentential frameworks exclusively deals with selective abduction (diagnostic reasoning $)^{4}$ and relates to the idea of preserving consistency. Exclusively considering the sentential view of abduction does not enable us to say much about creative processes in science, and, therefore, about the nomological and most interesting creative aspects of abduction. It mainly refers to the selective (diagnostic) aspects of reasoning and to the idea that abduction is mainly an inference to the best explanation [35]: when used to express the creative events it is either empty or replicates the well-known Gestalt model of radical innovation. It is empty because the sentential view stops any attempt to analyze the creative processes: the event of creating something new is considered so radical and instantaneous that its irrationality is immediately involved.

For Peirce abduction is an inferential process that includes all the operations whereby hypotheses and theories are constructed. Hence abduction has to be considered as a kind of ampliative inference that, as already stressed, is not logical and truth preserving: indeed valid deduction does not yield any new information, for example new hypotheses previously unknown.

From the point of view of computational philosophy ${ }^{5}$ the sentential models of theoretical abduction are limited, because they do not capture various reasoning tasks [33]:

1. the role of statistical explanations, where what is explained follows only probabilistically and not deductively from the laws and other tools that do the explaining;

2. the sufficient conditions for explanation;

3. the fact that sometimes the explanations consist of the application of schemas that fit a phenomenon into a pattern without realizing a deductive inference;

4. the idea of the existence of high-level kinds of creative abductions;

\footnotetext{
${ }^{4}$ As previously indicated, it is important to distinguish between selective (abduction that merely selects from an encyclopedia of pre-stored hypotheses), and creative abduction (abduction that generates new hypotheses).

${ }^{5}$ Computational philosophy (CP) aims at investigating many important concepts and problems of the philosophical and epistemological tradition in a new way by taking advantage of information-theoretic, cognitive, and artificial intelligence methodologies. I maintain that the results of computational philosophy meet the classical requirements of some Peircian "pragmatic ambitions". Indeed, more than a hundred years ago, the American philosopher C. S. Peirce, when working on logical and philosophical problems, suggested the concept of pragmatism ("pragmaticism", in his own words) as a logical criterion to analyze what words and concepts express through their practical meaning. In $1994 \mathrm{I}$ founded at the University of Pavia, Pavia, Italy the so-called "Computational Philosophy Laboratory", $<$ http://www.unipv.it/webphilos_lab/>
} 
5. the existence of model-based abductions (cf. the following section);

6 . the fact that explanations usually are not complete but only furnish partial accounts of the pertinent evidence [65];

7. the fact that one of the most important virtues of a new scientific hypothesis (or of a scientific theory) is its power of explaining new, previously unknown facts: "[...] these facts will be [...] unknown at the time of the abduction, and even more so must the auxiliary data which help to explain them be unknown. Hence these future, so far unknown explananda, cannot be among the premises of an abductive inference" [20], observations become real and explainable only by means of new hypotheses and theories, once discovered by abduction.

\subsection{Model-Based Abduction and Its External Dimension}

Computational philosophy taught us how to provide a suitable framework for constructing actual models of the most interesting cases of conceptual changes in science: we do not have to limit ourselves to the sentential view of theoretical abduction but we have to consider a broader inferential one: the model-based sides of creative abduction (cf. below).

From Peirce's philosophical point of view, all thinking is in signs, and signs can be icons, indices or symbols. Moreover, all inference is a form of sign activity, where the word sign includes "feeling, image, conception, and other representation" [52, 5.283], and, in Kantian words, all synthetic forms of cognition. That is, a considerable part of the thinking activity is model-based. Of course model-based reasoning acquires its peculiar creative relevance when embedded in abductive processes, so that we can individuate a model-based abduction. Hence, we must think in terms of model-based abduction (and not in terms of sentential abduction) to explain complex processes like scientific conceptual change. Different varieties of model-based abductions [33] are related to the high-level types of scientific conceptual change [see, for instance, [62].

Following Nersessian [48, 49], the term "model-based reasoning" is used to indicate the construction and manipulation of various kinds of representations, not mainly sentential and/or formal, but mental and/or related to external mediators. Although controversy arises as to whether there is any form of representation other than strings of symbols, it is possible, following [27] to assume the existence of at least three kinds of mental representations:

1. propositional representations (strings of symbols such as "the pot is on the table");

2. mental models (structural analogs of real world or imagined situations, such as a pot being on a table);

3. images (a mental model from a specific perspective, such as looking down on the pot on the table from above).

Obvious examples of model-based reasoning are constructing and manipulating visual representations, thought experiment, analogical reasoning, but also for example the so-called "tunnel effect" [14], occurring when models are built at the intersection of some operational interpretation domain - with its interpretation capabilities - and a new ill-known domain.

Manipulative abduction [35] - contrasted with theoretical abduction - happens when we are thinking through doing and not only, in a pragmatic sense, about doing. So 


\section{Multimodal Abduction}

the idea of manipulative abduction goes beyond the well-known role of experiments as capable of forming new scientific laws by means of the results (nature's answers to the investigator's question) they present, or of merely playing a predictive role (in confirmation and in falsification). Manipulative abduction refers to an extratheoretical behavior that aims at creating communicable accounts of new experiences to integrate them into previously existing systems of experimental and linguistic (theoretical) practices. The existence of this kind of extra-theoretical cognitive behavior is also testified by the many everyday situations in which humans are perfectly able to perform very efficacious (and habitual) tasks without the immediate possibility of realizing their conceptual explanation. In the following sections manipulative abduction will be considered from the perspective of the relationship between internal and external representations.

\section{Mimetic and Creative Representations}

Human brains organize themselves through a semiotic activity that is reified in the external environment and then re-projected and reinterpreted through new configurations of neural networks and chemical processes. I also think the externalization of mind can nicely account for low-level semiotic processes of meaning creation, bringing up the question of how could higher-level processes be comprised and how would they interact with lower-level ones.

\subsection{External and Internal Representations}

I have illustrated in a previous paper [40] that through the mediation of the material culture the modern human mind for example can arrive to internally "think" the new complicated meaning of animals and people at the same time. We can account for this process of externalization from an impressive cognitive point of view.

I maintain that representations are external and internal. We can say that

- external representations are formed by external materials that express (through reification) concepts and problems already stored in the brain or that do not have a natural home in it;

- internalized representations are internal re-projections, a kind of recapitulations, (learning) of external representations in terms of neural patterns of activation in the brain. They can sometimes be "internally" manipulated like external objects and can originate new internal reconstructed representations through the neural activity of transformation and integration.

This process explains why human beings seem to perform both computations of a connectionist type ${ }^{6}$ such as the ones involving representations as

- (I Level) patterns of neural activation that arise as the result of the interaction

\footnotetext{
${ }^{6}$ Here the reference to the word "connectionism" is used on the plausible assumption that all mental representations are brain structures: verbal and the full range of sensory representations are neural structures endowed with their chemical functioning (neurotransmitters and hormones) and electrical activity (neurons fire and provide electrical inputs to other neurons). In this sense we can reconceptualize cognition neurologically: for example the solution of a problem can be seen as a process in which one neural structure representing an explanatory target generates another neural structure that constitutes a hypothesis for the solution.
} 
between body and environment (and suitably shaped by the evolution and the individual history): pattern completion or image recognition,

and computations that use representations as

- (II Level) derived combinatorial syntax and semantics dynamically shaped by the various external representations and reasoning devices found or constructed in the environment (for example geometrical diagrams); they are neurologically represented contingently as pattern of neural activations that "sometimes" tend to become stabilized structures and to fix and so to permanently belong to the I Level above.

The I Level originates those sensations (they constitute a kind of "face" we think the world has), that provide room for the II Level to reflect the structure of the environment, and, most important, that can follow the computations suggested by these external structures. It is clear we can now conclude that the growth of the brain and especially the synaptic and dendritic growth are profoundly determined by the environment.

When the fixation is reached the patterns of neural activation no longer need a direct stimulus from the environment for their construction. In a certain sense they can be viewed as fixed internal records of external structures that can exist also in the absence of such external structures. These patterns of neural activation that constitute the I Level Representations always keep record of the experience that generated them and, thus, always carry the II Level Representation associated to them, even if in a different form, the form of memory and not the form of a vivid sensorial experience. Now, the human agent, via neural mechanisms, can retrieve these II Level Representations and use them as internal representations or use parts of them to construct new internal representations very different from the ones stored in memory $[16] .^{7}$

I think there are two basic kinds of external representations active in this process of externalization of the mind: creative and mimetic. Mimetic external representations mirror concepts and problems that are already represented in the brain and need to be enhanced, solved, further complicated, etc. so they sometimes can creatively give rise to new concepts and meanings. In the examples I will illustrate in the following sections it will be clear how for instance a mimetic geometric representation can become creative and give rise to new meanings and ideas in the hybrid interplay between brains and suitable "cognitive niches" 8 that consequently are appropriately reshaped.

In the following section I will illustrate some fundamental aspects of the interplay above in the light of basic semiotic aspects of abductive reasoning.

\section{Model-Based Abduction and Semiosis beyond Peirce}

What exactly is model-based abduction from a philosophical point of view? I have already said that Peirce stated that all thinking is in signs, and signs can be icons,

\footnotetext{
${ }^{7}$ The role of external representations has already been stressed in some central traditions of cognitive science and artificial intelligence, from the area of distributed and embodied cognition and of robotics $[7,12,68]$ to the area of active vision and perception $[17,66]$.

${ }^{8}$ This expression, used in the different framework of the problem of language as biological adaptation to the environment appears very appropriate also in this context [58].
} 


\section{Multimodal Abduction}

indices, or symbols and that all inference is a form of sign activity, where the word sign includes "feeling, image, conception, and other representation" [52, 5.283]. In this light it can be maintained that a considerable part of the creative meaning processes is model-based. Moreover, a considerable part of meaning creation processes (not only in science) occurs in the middle of a relationship between brains and external objects and tools that have received cognitive and/or epistemological delegations (cf. the previous and the following subsection).

Following this Peircian perspective about inference I think it is extremely useful from a cognitive point of view to consider the concept of reasoning in a very broad way (cf. also [5, p. 8]). We have three cases:

1. reasoning can be fully conscious and typical of high-level worked-out ways of inferring, like in the case of scientists' and professionals' performances;

2. reasoning can be "acritical" [52, 5.108], which includes every day inferences in conversation and in various ordinary patterns of thinking;

3. reasoning can resort to "operations of the mind which are logically analogous to inference excepting only that they are unconscious and therefore uncontrollable and therefore not subject to logical criticism" [52, 5.108].

Immediately Peirce adds a note to the third case "But that makes all the difference in the world; for inference is essentially deliberate, and self-controlled. Any operation which cannot be controlled, any conclusion which is not abandoned, not merely as soon as criticism has pronounced against it, but in the very act of pronouncing that decree, is not of the nature of rational inference - is not reasoning" ( $i b i d$.).

As Colapietro clearly states [13, p. 140], it seems that for Peirce human beings semiotically involve unwitting trials and unconscious processes. Moreover, it seems clear that unconscious thought can be in some sense considered "inference", even if not rational; indeed, Peirce says, it is not reasoning. Peirce further indicates that there are in human beings multiple trains of thought at once but only a small fraction of them is conscious, nevertheless the prominence in consciousness of one train of thought is not to be interpreted an interruption of other ones.

In this Peircian perspective, which I adopt in this essay, where inferential aspects of thinking dominate, there is no intuition, in an anti-Cartesian way. We know all important facts about ourselves in an inferential abductive way:

[...] we first form a definite idea of ourselves as a hypothesis to provide a place in which our errors and other people's perceptions of us can happen. Furthermore, this hypothesis is constructed from our knowledge of "outward" physical facts, such things as the sounds we speak and the bodily movements we make, that Peirce calls signs [5, p. 8].

Recognizing in a series of material, physical events, that they make up a series of signs, is to know the existence of a "mind" (or of a group of minds) and to be absorbed in making, manifesting, or reacting to a series of signs is to be absorbed in "being a mind". "[...] all thinking is dialogic in form" [52, 6.338], both at the intrasubjective $^{9}$ and intersubjective level, so that we see ourselves exactly as others

9 "One's thoughts are what he is 'saying to himself', that is saying to that other self that is just coming to life in the flow of time. When one reasons, it that critical self that one is trying to persuade: and all thought whatsoever is a sign, and is mostly in the nature of language" [52, 5.421]. 
see us, or see them exactly as they see themselves, and we see ourselves through our own speech and other interpretable behaviors, just others see us and themselves in the same way, in the commonality of the whole process [5, p. 10].

As I will better explain later on in the following sections, in this perspective minds are material like brains, in so far as they consist in intertwined internal and external semiotic processes: "[...] the psychologists undertake to locate various mental powers in the brain; and above all consider it as quite certain that the faculty of language resides in a certain lobe; but I believe it comes decidedly nearer the truth (though not really true) that language resides in the tongue. In my opinion it is much more true that the thoughts of a living writer are in any printed copy of his book than they are in his brain" [52, 7.364].

\subsection{Man is an External Sign}

Peirce's semiotic motto "man is an external sign" is very clear about the materiality of mind and about the fact that the conscious self ${ }^{10}$ is a cluster actively embodied of flowing intelligible signs:

It is sufficient to say that there is no element whatever of man's consciousness which has not something corresponding to it in the word; and the reason is obvious. It is that the word or sign which man uses is the man himself. For, as the fact that every thought is a sign, taken in conjunction with the fact that life is a train of thoughts, proves that man is a sign; so, that every thought is an external sign, proves that man is an external sign. That is to say, the man and the external sign are identical, in the same sense in which the words homo and man are identical. Thus my language is the sum total of myself; for the man is the thought $[52,5.314]$.

It is by way of signs that we ourselves are semiotic processes - for example a more or less coherent cluster of narratives. If all thinking is in signs it is not true that thoughts are in us because we are in thoughts.

I think it is at this point clearer what I meant in section 1.3, when I explained the concept of model-based abduction and said, adopting a Peircian perspective, that all thinking is in signs, and signs can be icons, indices, or symbols and that, moreover, all inference is a form of sign activity, where the word sign includes feeling, image, conception, and other representation. The model-based aspects of human cognition are central, given the central role played for example by signs like images and feeling in the inferential activity "[...] man is a sign developing according to the laws of inference. $[. .$.$] the entire phenomenal manifestation of mind is a sign resulting from$ inference" [52, 5.312 and 5.313].

Moreover, the "person-sign" is future-conditional, that is not fully formed in the present but depending on the future destiny of the concrete semiotic activity (future thoughts and experience of the community) in which she will be involved. If Peirce maintains that when we think we appear as a sign $[52,5.283]$ and, moreover, that everything is present to us is a phenomenal manifestation of ourselves, then feelings, images, diagrams, conceptions, schemata, and other representations are phenomenal manifestations that become available for interpretations and thus are guiding our

\footnotetext{
${ }^{10}$ Consciousness arises as "a sort of public spirit among the nerve cells" [52, 1.354].
} 


\section{Multimodal Abduction}

actions in a positive or negative way. They become signs when we think and interpret them. It is well-known that for Peirce all semiotic experience - and thus abduction - is also providing a guide for action. Indeed the whole function of thought is to produce habits of action. ${ }^{11}$

Let us summarize some basic semiotic ideas that will be of help in the further clarification of the cognitive and computational features of model-based and manipulative abduction. One of the central property of signs is their reinterpretability. This occurs in a social process where signs are referred to material objects.

As it is well-known for Peirce iconic signs are based on similarity alone, the psychoanalytic patient who thought he was masturbating when piloting the plane interpreted the cloche as an extension of his body, and an iconic sign of the penis; an ape may serve as an icon of a human. Indexical signs are based on contiguity and dynamic relation to the object, a sign which refers to an object that it denotes by virtue of being "really affected" by that object: a certain grimace indicates the presence of pain, the rise of the column of mercury in a thermometer is a sign of a rise in temperature, indexical signs are also the footprints in the sand or a rap on the door. Consequently we can say indexical signs "point". A symbol refers to an artificial or conventional ("by virtue of a law") interpretation of a sign, the sign $\infty$ used by mathematicians would be an example of Peirce's notion of symbol, almost all words in language, except for occasional onomatopoeic qualities, are symbols in this sense, associated with referents in a wholly arbitrary manner.

We have to immediately note that from the semiotic point of view feelings too are signs that are subject to semiotic interpretations at different levels of complexity. Peirce considered feelings elementary phenomena of mind, comprising all that is immediately present, such as pain, sadness, cheerfulness. He believes that a feeling is a state of mind possessing its own living qualities independent of any other state of the mind. Neither icon, index, nor symbol actually functions as a sign until it is interpreted and recognized in a semiotic activity and code. To make an example, it is the evolutionary kinship that makes the ape an icon of the man, in itself the similarity of two animals does not mean anything.

Where cognition is merely possible, sign action, or semiosis, is working. Knowledge is surely inferential as well as abduction, that like any inference requires three elements: a sign, the object signified, and the interpretant. Everywhere " $A$ signifies $B$ to $C^{\prime \prime}$.

There is a continuous activity of interpretation and part of this activity - as we will see - is abductive. The Peircian notion of interpretant plays the role of explaining the activity of interpretation that is occurring in semiosis. The interpretant does not necessarily refer to an actual person or mind, an actual interpreter. For instance the communication to be found in a beehive ${ }^{12}$ where the bees are able to communicate with the others by means of signs is an example of a kind of "mindless" triadic semiosis: indeed we recognize that a sign has been interpreted not because we have observed a mental action but by observing another material sign. To make another example, the person recognizing the thermometer as a thermometer is an interpretant, as she generates in her brain a thought. In this case the process is conscious, but also

\footnotetext{
${ }^{11}$ On this issue cf. for example the contributions contained in recent special issue of the journal Semiotica devoted to abduction [60].

12 This kind of communication is studied in [47].
} 
unconscious or emotional interpretants are widespread. Again, a person points (index) up at the sky and his companion looks up (interpretant) to see the object of the sign. Someone else might call out "What do you see up there?" that is also another interpretant of the original sign. As noted by Brent "For Peirce, any appropriate response to a sign is acting as another sign of the object originally signified. A sunflower following the sun across the sky with its face is also an interpretant. Peirce uses the word interpretant to stand for any such development of a given sign" [5, p. $12]$.

Finally, an interpretant may be the thought of another person, but may as well be simply the further thought of the first person, for example in a soliloquy the succeeding thought is the interpretant of the preceding thought so that an interpretant is both the interpretant of the thought that precedes it and the object of the interpretant thought that succeeds it. In soliloquy sign, object, and interpretant are all present in the single train of thought.

Interpretants, mediating between signs and their objects have three distinct levels in hierarchy: feelings, actions, and concepts or habits (that is various generalities as responses to a sign). They are the effect of a sign process. The interpretant produced by the sign can lead to a feeling (emotional interpretant), or to a muscular or mental effort, that is to a kind of action - energetic interpretant (not only outward, bodily action, but also purely inward exertions like those "mental soliloquies strutting and fretting on the stage of imagination" - [13, p. 142]. Finally, when it is related to the abstract meaning of the sign, the interpretant is called logical, as a generalization requiring the use of verbal symbols. It is a further development of semiosis in the hierarchy of iconic, enactive, and symbolic communication: in short, it is "an interpreting thought", related for instance not only to the intellectual activity but also to initiate the ethical action in so far as a "modification of a person's tendencies toward action" [52, 5.476].

The logical interpretants are able to translate percepts, emotions, unconscious needs, and experience needs, and so to mediate their meanings to arrive to provisional stabilities. They can lead to relatively stable cognitive or intellectual habits and belief changes as self-controlled achievements like many abductive conceptual results, that Peirce considers the most advanced form of semiosis and the ultimate outcome of a sign. Indeed abduction - hypothesis - is the first step toward the formation of cognitive habits: "every concept, every general proposition of the great edifice of science, first came to us as a conjecture. These ideas are the first logical interpretants of the phenomena that suggested them, and which, as suggesting them, are signs" [52, 5.480].

Ortogonal to the classification of interpretants as emotional, energetic, and logical is the alternate classification given by Peirce: interpretants can also be immediate, dynamic, and normal. Some interpreters consider this classification a different way of expressing the first one. It is sufficient to note this classification can be useful in studying the formation of a subclass of debilitating and facilitating psychic habits [13, pp. 144-146]. Colapietro proposes the concept of quasi-final interpretants - as related to the Peircian normal interpretants - as "effective in the minimal sense that they allow the conflict-ridden organism to escape being paralyzed agent: they permit the bodyego to continue its ongoing negotiations with these conflicting demands, even if only in a precarious and even debilitating manner. In brief, they permit the body-ego to go 


\section{Multimodal Abduction}

on" $[13$, p. 146]. For instance there are some sedimented unsconscious reactions of this type in immediate puzzling environments - later on useless and stultifying in wider settings - but there also is the recurrent reflective and - provisionally - productive use of fallacious ways of reasoning like hasty generalizations and other arguments [67].

In the following sections I will describe how the interplay of signs, objects, and interpretants is working in important aspects of abductive reasoning. Of course modelbased cognition acquires its peculiar creative relevance when embedded in abductive processes. I will show some examples of model-based inferences. It is well known the importance Peirce ascribed to diagrammatic thinking (a kind of iconic thinking), as shown by his discovery of the powerful system of predicate logic based on diagrams or "existential graphs". As we have already stressed, Peirce considers inferential any cognitive activity whatever, not only conscious abstract thought; he also includes perceptual knowledge and subconscious cognitive activity. For instance in subconscious mental activities visual representations play an immediate role [60].

Many commentators always criticized the Peircian ambiguity in treating abduction in the same time as inference and perception. It is important to clarify this problem, because perception and imagery are kinds of that model-based cognition which we are exploiting to explain abduction: in [40] I conclude we can render consistent the two views, beyond Peirce, but perhaps also within the Peircian texts, taking advantage of the concept of multimodal abduction, which depicts hybrid aspects of abductive reasoning.

Thagard [63,64] observes, that abductive inference can be visual as well as verbal, and consequently acknowledges the sentential, model-based, and manipulative nature of abduction we have illustrated above. Moreover, both data and hypotheses can be visually represented:

For example, when I see a scratch along the side of my car, I can generate the mental image of grocery cart sliding into the car and producing the scratch. In this case both the target (the scratch) and the hypothesis (the collision) are visually represented. [...] It is an interesting question whether hypotheses can be represented using all sensory modalities. For vision the answer is obvious, as images and diagrams can clearly be used to represent events and structures that have causal effects [64].

Indeed hypotheses can be also represented using other sensory modalities:

[...] I may recoil because something I touch feels slimy, or jump because of a loud noise, or frown because of a rotten smell, or gag because something tastes too salty. Hence in explaining my own behavior my mental image of the full range of examples of sensory experiences may have causal significance. Applying such explanations of the behavior of others requires projecting onto them the possession of sensory experiences that I think are like the ones that I have in similar situations. [...] Empathy works the same way, when I explain people's behavior in a particular situation by inferring that they are having the same kind of emotional experience that I have in similar situations [64].

Thagard illustrates the case in which a professor with a recently rejected manuscript is frowning: another colleagues can empathizes by remembering how annoying she felt in the same circumstances, projecting a mental image onto the colleague that is a nonverbal representation able to explain the frown. Of course a verbal explanation can be 
added, but this just complements the empathetic one. It is in this sense that Thagard concludes that abduction can be fully multimodal, in that both data and hypotheses can have a full range of verbal and sensory representations. Some basic aspects of this constitutive hybrid nature of abduction - involving words, sights, images, smells, etc. but also kinesthetic experiences and other feelings such as pain - will be investigated in the following sections.

\section{Constructing Meaning through Mimetic and Creative External Objects}

\subsection{Constructing Meaning through Manipulative Abduction}

Manipulative abduction occurs when many external things, usually inert from the semiotic point of view, can be transformed into what I have called, in the case of scientific reasoning, "epistemic mediators" [35] that give rise to new signs, new chances for interpretants, and new interpretations.

We can cognitively account for this process of externalization ${ }^{13}$ taking advantage of the concept of manipulative abduction (cf. Figure 3). It happens when we are thinking through doing and not only, in a pragmatic sense, about doing. It happens, for instance, when we are creating geometry constructing and manipulating an external suitably realized icon like a triangle looking for new meaningful features of it, like in the case given by Kant in the "Transcendental Doctrine of Method" ([37], and the following subsection). It refers to an extra-theoretical behavior that aims at creating communicable accounts of new experiences to integrate them into previously existing systems of experimental and linguistic (semantic) practices.

Gooding [18] refers to this kind of concrete manipulative reasoning when he illustrates the role in science of the so-called "construals" that embody tacit inferences in procedures that are often apparatus and machine based. The embodiment is of course an expert manipulation of meaningful semiotic objects in a highly constrained experimental environment, and is directed by abductive movements that imply the strategic application of old and new templates of behavior mainly connected with extra-rational components, for instance emotional, esthetical, ethical, and economic.

The hypothetical character of construals is clear: they can be developed to examine or discard further chances, they are provisional creative organization of experience and some of them become in their turn hypothetical interpretations of experience, that is more theory-oriented, their reference/meaning is gradually stabilized in terms of established observational practices. Step by step the new interpretation - that at the beginning is completely "practice-laden" - relates to more "theoretical" modes of understanding (narrative, visual, diagrammatic, symbolic, conceptual, simulative), closer to the constructive effects of theoretical abduction. When the reference/meaning is stabilized the effects of incommensurability with other established observations can become evident. But it is just the construal of certain phenomena that can be shared by the sustainers of rival theories. Gooding [18] shows how Davy and Faraday could see the same attractive and repulsive actions at work in the phenomena they re-

\footnotetext{
${ }^{13}$ A significant contribution to the comprehension of this process in terms of the so-called "disembodiment of the mind" derives from some studies in the field of cognitive paleoanthropology that describe various related aspects of the birth of the material "culture". In [40] I have illustrated this issue relating it to the Turing ideas on "unorganized" and "organized" brains.
} 


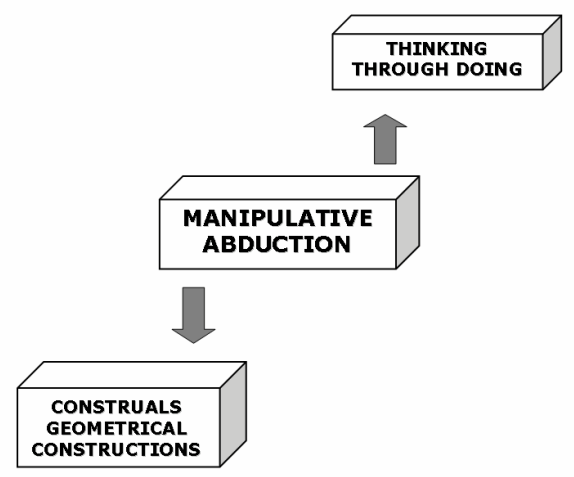

FIG. 3. Manipulative abduction.

spectively produced; their discourse and practice as to the role of their construals of phenomena clearly demonstrate they did not inhabit different, incommensurable worlds in some cases. Moreover, the experience is constructed, reconstructed, and distributed across a social network of negotiations among the different scientists by means of construals.

It is difficult to establish a list of invariant behaviors that are able to describe manipulative abduction in science. As illustrated above, certainly the expert manipulation of objects in a highly semiotically constrained experimental environment implies the application of old and new templates of behavior that exhibit some regularities. The activity of building construals is highly conjectural and not immediately explanatory: these templates are hypotheses of behavior (creative or already cognitively present in the scientist's mind-body system, and sometimes already applied) that abductively enable a kind of epistemic "doing". Hence, some templates of action and manipulation can be selected in the set of the ones available and pre-stored, others have to be created for the first time to perform the most interesting creative cognitive accomplishments of manipulative abduction.

Moreover, I think that a better understanding of manipulative abduction at the level of scientific experiment could improve our knowledge of induction, and its distinction from abduction: manipulative abduction could be considered as a kind of basis for further meaningful inductive generalizations. Different generated construals can give rise to different inductive generalizations.

Some common features of these tacit templates that enable us to manipulate things and experiments in science to favor meaning formation are related to: 1 . sensibility towards the aspects of the phenomenon which can be regarded as curious or anomalous; manipulations have to be able to introduce potential inconsistencies in the received knowledge (Oersted's report of his well-known experiment about electromagnetism is devoted to describe some anomalous aspects that did not depend on any particular theory of the nature of electricity and magnetism; Ampère's construal of experiment on electromagnetism - exploiting an artifactual apparatus to produce a static equi- 
librium of a suspended helix that clearly shows the role of the "unexpected"); 2 . preliminary sensibility towards the dynamical character of the phenomenon, and not to entities and their properties, common aim of manipulations is to practically reorder the dynamic sequence of events in a static spatial one that should promote a subsequent bird's-eye view (narrative or visual-diagrammatic); 3. referral to experimental manipulations that exploit artificial apparatus to free new possibly stable and repeatable sources of information about hidden knowledge and constraints (Davy well-known set-up in terms of an artifactual tower of needles showed that magnetization was related to orientation and does not require physical contact). Of course this information is not artificially made by us: the fact that phenomena are made and manipulated does not render them to be idealistically and subjectively determined; 4. various contingent ways of epistemic acting: looking from different perspectives, checking the different information available, comparing subsequent events, choosing, discarding, imaging further manipulations, re-ordering and changing relationships in the world by implicitly evaluating the usefulness of a new order (for instance, to help memory).

From the general point of view of everyday situations manipulative abductive reasoning exhibits other very interesting templates: 5. action elaborates a simplification of the reasoning task and a redistribution of effort across time when we "need to manipulate concrete things in order to understand structures which are otherwise too abstract" [56], or when we are in presence of redundant and unmanageable information; 6. action can be useful in presence of incomplete or inconsistent information - not only from the "perceptual" point of view - or of a diminished capacity to act upon the world: it is used to get more data to restore coherence and to improve deficient knowledge; 7 . action as a control of sense data illustrates how we can change the position of our body (and/or of the external objects) and how to exploit various kinds of prostheses (Galileo's telescope, technological instruments and interfaces) to get various new kinds of stimulation: action provides some tactile and visual information (e. g., in surgery), otherwise unavailable; 8. action enables us to build external artifactual models of task mechanisms instead of the corresponding internal ones, that are adequate to adapt the environment to the agent's needs: experimental manipulations exploit artificial apparatus to free new possible stable and repeatable sources of information about hidden knowledge and constraints.

The whole activity of manipulation is devoted to build various external epistemic mediators ${ }^{14}$ that function as versatile semiotic tools able to provide an enormous new source of information and knowledge. Therefore, manipulative abduction represents a kind of redistribution of the epistemic and cognitive effort to manage objects and information that cannot be immediately represented or found internally (for example exploiting the resources of visual imagery). ${ }^{15}$

If we see scientific discovery like a kind of opportunistic ability of integrating information from many kinds of simultaneous constraints to produce explanatory hypotheses that account for them all, then manipulative abduction will play the role of eliciting possible hidden constraints by building external suitable experimental struc-

\footnotetext{
${ }^{14}$ I derive this expression from the cognitive anthropologist Hutchins, that coins the expression "mediating structure" to refer to various external tools that can be built to cognitively help the activity of navigating in modern but also in "primitive" settings $[25,26]$.

${ }^{15}$ It is difficult to preserve precise spatial relationships using mental imagery, especially when one set of them has to be moved relative to another.
} 
tures.

\subsection{Manipulating Meanings through External Semiotic Anchors}

If the structures of the environment play such an important role in shaping our semiotic representations and, hence, our cognitive processes, we can expect that physical manipulations of the environment receive a great cognitive relevance.

Several authors have pointed out the role that physical actions can have at a cognitive level. In this sense Kirsh and Maglio [29] distinguish actions into two categories, namely pragmatic actions and epistemic actions. Pragmatic actions are the actions that an agent performs in the environment in order to bring itself physically closer to a goal. In this case the action modifies the environment so that the latter acquires a configuration that helps the agent to reach a goal which is understood as physical, that is, as a desired state of affairs. Epistemic actions are the actions that an agent performs in a semiotic environment in order to discharge the mind of a cognitive load or to extract information that is hidden or that would be very hard to obtain only by internal computation.

In this section I want to focus specifically on the relationship that can exist between manipulations of the environment and representations. In particular, I want to examine whether external manipulations can be considered as means to construct external representations.

If a manipulative action performed upon the environment is devoted to create a configuration of signs that carries relevant information, that action will well be able to be considered as a cognitive semiotic process and the configuration of elements it creates will well be able to be considered an external representation. In this case, we can really speak of an embodied cognitive process in which an action constructs an external representation by means of manipulation. We define cognitive manipulating as any manipulation of the environment devoted to construct external configurations that can count as representations.

An example of cognitive manipulating is the diagrammatic demonstration illustrated in Figure 4, taken from the field of geometry. In this case a simple manipulation of the triangle in Figure 4(a) gives rise to an external configuration - Figure 4 (b) - that carries relevant semiotic information about the internal angles of a triangle "anchoring" new meanings.

(a)

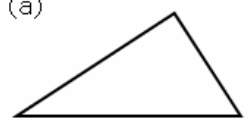

(b)

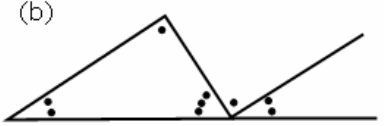

FIG. 4: Diagrammatic demonstration that the sum of the internal angles of any triangle is $180^{\circ}$. (a) Triangle. (b) Diagrammatic manipulation/construction.

The entire process through which an agent arrives at a physical action that can 
count as cognitive manipulating can be understood by means of the concept of manipulative abduction [35]. Manipulative abduction is a specific case of cognitive manipulating in which an agent, when faced with an external situation from which it is hard or impossible to extract new meaningful features of an object, selects or creates an action that structures the environment in such a way that it gives information which would be otherwise unavailable and which is used specifically to infer explanatory hypotheses.

In this way the semiotic result is achieved on external representations used in lieu of the internal ones. Here action performs an epistemic and not a merely performatory role, for example relevant to abductive reasoning.

\subsection{Geometrical Construction is a Kind of Manipulative Abduction}

Let's quote Peirce's passage about mathematical constructions. Peirce says that mathematical and geometrical reasoning "consists in constructing a diagram according to a general precept, in observing certain relations between parts of that diagram not explicitly required by the precept, showing that these relations will hold for all such diagrams, and in formulating this conclusion in general terms. All valid necessary reasoning is in fact thus diagrammatic" [52, 1.54]. This passage clearly refers to a situation like the one I have illustrated in the previous subsection. This kind of reasoning is also called by Peirce "theorematic" and it is a kind of "deduction" necessary to derive significant theorems: "[...] is one which, having represented the conditions of the conclusion in a diagram, performs an ingenious experiment upon the diagram, and by observation of the diagram, so modified, ascertains the truth of the conclusion" $[52,2.267]$. The experiment is performed with the help of "imagination upon the image of the premiss in order from the result of such experiment to make corollarial deductions to the truth of the conclusion" [54, IV, p. 38]. The "corollarial" reasoning is mechanical (Peirce thinks it can be performed by a "logical machine") and not creative, "A Corollarial Deduction is one which represents the condition of the conclusion in a diagram and finds from the observation of this diagram, as it is, the truth of the conclusion" [52, 2.267] (cf. also [22]).

In summary, the point of theorematic reasoning is the transformation of the problem by establishing an unnoticed point of view to get interesting - and possibly new insights. The demonstrations of theorems in mathematics are examples of theorematic deduction.

Not dissimilarly Kant says that in geometrical construction of external diagrams "[... I I must not restrict my attention to what I am actually thinking in my concept of a triangle (this is nothing more than the mere definition); I must pass beyond it to properties which are not contained in this concept, but yet belong to it" [28, A718-B746, p. 580].

We have seen that manipulative abduction is a kind of abduction, usually modelbased, that exploits external models endowed with delegated (and often implicit) cognitive and semiotic roles and attributes.

1. The model (diagram) is external and the strategy that organizes the manipulations is unknown a priori.

2. The result achieved is new (if we, for instance, refer to the constructions of the 


\section{Multimodal Abduction}

first creators of geometry), and adds properties not contained before in the concept (the Kantian to "pass beyond" or "advance beyond" the given concept [28, A154B193/194, p. 192]). ${ }^{16}$

Iconicity in theorematic reasoning is central. Peirce, analogously to Kant, maintains that "philosophical reasoning is reasoning with words; while theorematic reasoning, or mathematical reasoning is reasoning with specially constructed schemata" $[52$, 4.233]; moreover, he uses diagrammatic and schematic as synonyms, thus relating his considerations to the Kantian tradition where schemata mediate between intellect and phenomena. ${ }^{17}$ The following is the famous passage in the Critique of Pure Reason ("Transcendental Doctrine of Method"):

Suppose a philosopher be given the concept of a triangle and he be left to find out, in his own way, what relation the sum of its angles bears to a right angle. He has nothing but the concept of a figure enclosed by three straight lines, and possessing three angles. However long he meditates on this concept, he will never produce anything new. He can analyse and clarify the concept of a straight line or of an angle or of the number three, but he can never arrive at any properties not already contained in these concepts. Now let the geometrician take up these questions. He at once begins by constructing a triangle. Since he knows that the sum of two right angles is exactly equal to the sum of all the adjacent angles which can be constructed from a single point on a straight line, he prolongs one side of his triangle and obtains two adjacent angles, which together are equal to two right angles. He then divides the external angle by drawing a line parallel to the opposite side of the triangle, and observes that he has thus obtained an external adjacent angle which is equal to an internal angle - and so on. ${ }^{18}$ In this fashion, through a chain of inferences guided throughout by intuition, he arrives at a fully evident and universally valid solution of the problem [28, A716-B744, pp. 578-579].

As we have already said, for Peirce the whole mathematics consists in building diagrams that are "[...] (continuous in geometry and arrays of repeated signs/letters in algebra) according to general precepts and then [in] observing in the parts of these diagrams relations not explicitly required in the precepts" $[52,1.54]$. Peirce contends that this diagrammatic nature is not clear if we only consider syllogistic reasoning "which may be produced by a machine" but becomes extremely clear in the case of the "logic of relatives, where any premise whatever will yield an endless series of conclusions, and attention has to be directed to the particular kind of conclusion desired" [55, pp. 11-23].

In ordinary geometrical proofs auxiliary constructions are present in terms of "conveniently chosen" figures and diagrams where strategic moves are important aspects of deduction. The system of reasoning exhibits a dual character: deductive and "hypothetical". Also in other - for example logical - deductive frameworks there is room for

\footnotetext{
${ }^{16}$ Of course in the case we are using diagrams to demonstrate already known theorems (for instance in didactic settings), the strategy of manipulations is not necessary unknown and the result is not new.

${ }^{17}$ Schematism, a fruit of the imagination is, according to Kant, "[...] an art concealed in the depths of the human soul, whose real modes of activity nature is hardly likely ever to allow us to discover, and to have open to our gaze" [28, A141-B181, p. 183].

${ }^{18}$ It is Euclid's Proposition XXXII, Book I, cf. above Figure 4.
} 
strategical moves which play a fundamental role in the generations of proofs. These strategical moves correspond to particular forms of abductive reasoning.

We know that the kind of reasoned inference that is involved in creative abduction goes beyond the mere relationship that there is between premises and conclusions in valid deductions, where the truth of the premises guarantees the truth of the conclusions, but also beyond the relationship that there is in probabilistic reasoning, which renders the conclusion just more or less probable. On the contrary, we have to see creative abduction as formed by the application of heuristic procedures that involve all kinds of good and bad inferential actions, and not only the mechanical application of rules. It is only by means of these heuristic procedures that the acquisition of new truths is guaranteed. Also Peirce's mature view illustrated above on creative abduction as a kind of inference seems to stress the strategic component of reasoning.

Many researchers in the field of philosophy, logic, and cognitive science have sustained that deductive reasoning also consists in the employment of logical rules in a heuristic manner, even maintaining the truth preserving character: the application of the rules is organized in a way that is able to recommend a particular course of actions instead of another one. Moreover, very often the heuristic procedures of deductive reasoning are performed by means of a model-based abduction where iconicity is central. We have seen that the most common example of creative abduction is the usual experience people have of solving problems in geometry in a model-based way trying to devise proofs using diagrams and illustrations: of course the attribute of creativity we give to abduction in this case does not mean that it has never been performed before by anyone or that it is original in the history of some knowledge.

Hence we have to say that theoretical model-based abductions - as so iconicity - also operate in deductive reasoning. Following Hintikka and Remes's analysis [21] proofs of general implication in first order logic need the use of instantiation rules by which "new" individuals are introduced, so they are "ampliative". In ordinary geometrical proofs auxiliary constructions are present in term of "conveniently chosen" figures and diagrams. In Beth's method of semantic tableaux the "strategic ability" to construct impossible configurations is undeniable $[20,50] .^{19}$

This means that also in many forms of deductive reasoning there are not only trivial and mechanical methods of making inferences but we have to use models and heuristic procedures that refer to a whole set of strategic principles. All the more reason that Bringsjord [6] stresses his attention on the role played by a kind of "model based deduction" that is "part and parcel" of our establishing Gödel's first incompleteness theorem, showing the model-based character of this great abductive achievement of formal thought..$^{20}$

I think the previous considerations also hold for Peircian theorematic reasoning: indeed Peirce further distinguished a "corollarial" and a "theoric" part within "theorematic reasoning", and connects theoric aspects to abduction [22, p. 293]. Of course, as already stressed, we have to remember this abductive aspect of mathematical reasoning is not in itself creative. It can be performed both in creative (to find new

\footnotetext{
${ }^{19}$ Also Aliseda $[1,2]$ provides interesting use of the semantic tableaux as a constructive representation of theories, where abductive expansions and revisions, derived from the belief revision framework, operate over them. The tableaux are so viewed as a kind of (non-deductive) reasoning where the effect of "deduction" is performed by means of abductive strategies.

${ }^{20}$ Many interesting relationships between model-based reasoning in creative reasoning and its possible deductive models are analyzed in $[3,44,46,45])$, also related to the formal treatment of inconsistencies.
} 


\section{Multimodal Abduction}

theorems and mathematical hypotheses) and non creative (merely "selective") ways, for example in the case we are using diagrams to demonstrate already known theorems (for instance in didactic settings), where selecting the strategy of manipulations is among chances not necessarily unknown and the result is not new. With respect to abduction in empirical sciences abduction in mathematics aims at hypothesizing ideal objects, which later we can possibly insert in a deductive apodictic and truth preserving framework.

The example of diagrams in geometry furnishes a semiotic and epistemological example of the nature of the cognitive interplay between internal neuronal representations (and embodied "cognitive" kinesthetic abilities) and external representations I have illustrated above: also for Peirce, more than a century before the new ideas derived from the field of distributed reasoning, the two aspects are intertwined in the pragmatic and semiotic view, going beyond the rigidity of the Kantian approach in terms of schematism. Diagrams are icons that take material and semiotic form in an external environment endowed with

- constraints depending on the specific cognitive delegation performed by human beings and

- the particular intrinsic constraints of the materiality at play.

Concrete manipulations on them can be done for instance to get new data and cognitive information and/or to simplify the problem at issue (cf. the epistemic templates illustrated above in subsection 4.1).

\subsection{The Semiosis of Re-Embodiment}

Some interesting semiotic aspects of the above illustrated process can be nicely analyzed. Imagine that a suitable fixed internal record exists - deriving from the cognitive exploitation of the previous suitable interplay with external structures - at the level of neural activation and that for instance it embeds an abstract concept endowed with all its features, for example the concept of triangle. Now, the human agent, via neural mechanisms and bodily actions, can "re-embody" that concept by making an external perceivable sign, for instance available to the attention of other human or animal senses and brains. For instance that human agent can use what in semiotics is called a symbol (with its conventional character: $A B C$, for example), but also an icon of relations (a suitable diagram of a triangle), or a hybrid representation that will take advantage of both. In Peircian terms:

A representation of an idea is nothing but a sign that calls up another idea. When one mind desires to communicate an idea to another, he embodies his idea by making an outward perceptible image which directly calls up a like idea; and another mind perceiving that image gets a like idea. Two persons may agree upon a conventional sign which shall call up to them an idea it would not call up to anybody else. But in framing the convention they must have resorted to the primitive diagrammatic method of embodying the idea in an outward form, a picture. Remembering what likeness consists in, namely, in the natural attraction of ideas apart from habitual outward associations, I call those signs which stand for their likeness to them icons. 
Accordingly, I say that the only way of directly communicating an idea is by mean of an icon; and every indirect method of communicating an idea must depend for its establishment upon the use of an icon [53, 787, 26-28]. ${ }^{21}$

It is well-known that for Peirce every picture is a icon and thus every diagram, even if it lacks a sensuous similarity with the object, but just exhibits an analogy between the relations of the part of it and of the object:

Particularly deserving of notice are icons in which the likeness is aided by conventional rules. Thus, an algebraic formula is an icon, rendered such by the rules of commutation, association, and distribution of the symbols; that it might as well, or better, be regarded as a compound conventional sign. It may seem at first glance that it is an arbitrary classification to call an algebraic expression an icon; that it might as well, or better, be regarded as a compound of conventional sign. But it is not so. For a great distinguishing property of the icon is that by direct observation of it other truths concerning its object can de discovered than those which suffice to determine its construction. Thus, by means of two photographs a map can be drawn, etc. Given a conventional or other general sign of an object, to deduce any other truth than which it explicitly signifies, it is necessary, in all cases, to replace that sign by an icon. This capacity of revealing unexpected truth is precisely that wherein the utility of algebraic formulae consists, so that the icon in character is the prevailing one [53, 787, CSP 26-28].

Stressing the role of iconic dimensions of semiosis ${ }^{22}$ in the meantime celebrates the virtues of analogy, as a kind of "association by resemblance", as contrasted to "association by contiguity"

Human beings delegate cognitive features to external representations through semiotic attributions because for example in many problem solving situations the internal computation would be impossible or it would involve a very great effort because of human mind's limited capacity. First a kind of "alienation" is performed, second a recapitulation is accomplished at the neuronal level by re-representing internally that which was "discovered" outside. Consequently only later on we perform cognitive operations on the structure of data that synaptic patterns have "picked up" in an analogical way from the environment. We can maintain that internal representations used in cognitive processes like many events of meaning creation have a deep origin in the experience lived in the semiotic environment.

I already illustrated in section 2 that I think there are two kinds of artifacts that play the role of external objects (representations) active in this process of externalization of the mind: creative and mimetic. Mimetic external representations mirror concepts and problems that are already represented in the brain and need to be enhanced, solved, further complicated, etc. so they sometimes can creatively give rise to new concepts and meanings.

Following my perspective it is at this point evident that the "mind" transcends the boundary of the individual and includes parts of that individual's environment. It is

\footnotetext{
${ }^{21}$ We have to note that for Peirce an idea "[...] is not properly a conception, because a conception is not an idea at all, but a habit. But the repeated occurrence of a general idea and the experience of its utility, results in the formation or strengthening of that habit which is the conception" [52, 7.498].

${ }^{22}$ We have to remember that in this perspective any proposition is a diagram as well, because it represents a certain relation of symbols and indices.
} 


\section{Multimodal Abduction}

in this sense that the mind is semiotic and artificial.

\subsection{External Diagrammatization and Iconic Brain Co-Evolution}

Following our previous considerations it would seem that diagrams can be fruitfully seen from a semiotic perspective as external representations expressed through icons and symbols, aimed at simply "mimicking" various humans' internal images. However, they can also play the role of creative representations human beings externalize and manipulate not just to mirror the internal ways of thinking of human agents but to find room for concepts and new ways of inferring which cannot - at a certain time be found internally "in the mind".

In summary, we can say that

- diagrams as external iconic (often enriched by symbols) representations are formed by external materials that either mimic (through reification) concepts and problems already internally present in the brain or creatively express concepts and problems that do not have a semiotic "natural home" in the brain;

- subsequent internalized diagrammatic representations are internal re-projections, a kind of recapitulations, (learning) in terms of neural patterns of activation in the brain ("thoughts", in Peircian sense), of external diagrammatic representations. In some simple cases complex diagrammatic transformations - can be "internally" manipulated like external objects and can further originate new internal reconstructed representations through the neural activity of transformation and integration.

I have already stressed that this process explains - from a cognitive point of view why human agents seem to perform both computations of a connectionist type such as the ones involving representations as

- (I Level) patterns of neural activation that arise as the result of the interaction (also presemiotic) between body and environment (and suitably shaped by the evolution and the individual history): pattern completion or image recognition,

and computations that use representations as

- (II Level) derived combinatorial syntax and semantics dynamically shaped by the various artificial external representations and reasoning devices found or constructed in the semiotic environment (for example iconic representations); they are - more or less completely - neurologically represented contingently as patterns of neural activations that "sometimes" tend to become stabilized meaning structures and to fix and so to permanently belong to the I Level above.

It is in this sense we can say the "System of Diagrammatization", in Peircian words, allows for a self-controlled process of thought in the fixation of originally vague beliefs: as a system of learning, it is a process that leads from "absolutely undefined and unlimited possibility" $[52,6.217]$ to a fixation of belief and "by means of which any course of thought can be represented with exactitude" [52, 4.530]. Moreover, it is a system which could also improve other areas of science, beyond mathematics, like logic, it "greatly facilitates the solution of problems of Logic. [...] If logicians would 
only embrace this method, we should no longer see attempts to base their science on the fragile foundations of metaphysics or a psychology not based on logical theory" $[52,4.571]$.

As already stressed the I Level originates those sensations (they constitute a kind of "face" we think the world has), that provide room for the II Level to reflect the structure of the environment, and, most important, that can follow the computations suggested by the iconic external structures available. It is clear that in this case we can conclude that the growth of the brain and especially the synaptic and dendritic growth are profoundly determined by the environment. Consequently we can hypothesize a form of co-evolution between what we can call the iconic brain and the development of the external diagrammatic systems. Brains build iconic signs as diagrams in the external environment learning from them new meanings through interpretation (both at the spatial and sentential level) after having manipulated them.

When the fixation is reached - imagine for instance the example above, that fixes the sum of the internal angles of the triangle - the pattern of neural activation no longer needs a direct stimulus from the external spatial representation in the environment for its construction and can activate a "final logical interpretant", in Peircian terms. It can be neurologically viewed as a fixed internal record of an external structure (a fixed belief in Peircian terms) that can exist also in the absence of such external structure. The pattern of neural activation that constitutes the I Level Representation has kept record of the experience that generated it and, thus, carries the II Level Representation associated to it, even if in a different form, the form of semiotic memory and not the form of the vivid sensorial experience for example of the triangular construction drawn externally, over there, for instance in a blackboard. Now, the human agent, via neural mechanisms, can retrieve that II Level Representation and use it as an internal representation (and can use it to construct new internal representations less complicated than the ones previously available and stored in memory).

At this point we can easily understand the particular mimetic and creative role played by external diagrammatic representations in mathematics:

1. some concepts, meanings, and "ways of [geometrical] inferring" performed by the biological human agents appear hidden and tacit and can be rendered explicit by building external diagrammatic mimetic models and structures; later on the agent will be able to pick up and use what was suggested by the constraints and features intrinsic and immanent to their external semiotic materiality and the relative established conventionality: artificial languages, proofs, new figures, examples, etc.;

2. some concepts, meanings, and "new ways of inferring" can be discovered only through a problem solving process occurring in a distributed interplay between brains and external representations. I have called this process externalization (or disembodiment) of the mind: the representations are mediators of results obtained and allow human beings

(a) to re-represent in their brains new concepts, meanings, and reasoning devices picked up outside, externally, previously absent at the internal level and thus impossible: first, a kind of alienation is performed, second, a recapitulation is accomplished at the neuronal level by re-representing internally that which has 


\section{Multimodal Abduction}

been "discovered" outside. We perform cognitive geometric operations on the structure of data that synaptic patterns have "picked up" in an analogical way from the explicit diagrammatic representations in the environment;

(b) to re-represent in their brains portions of concepts, meanings, and reasoning devices which, insofar as explicit, can facilitate inferences that previously involved a very great effort because of human brain's limited capacity. In this case the thinking performance is not completely processed internally but in a hybrid interplay between internal (both tacit and explicit) and external iconic representations. In some cases this interaction is between the internal level and a computational tool which in turn can exploit iconic/geometrical representations to perform inferences (cf. above subsection 4.1).

An evolved mind is unlikely to have a natural home for complicated concepts like the ones geometry introduced, as such concepts do not exist in a definite way in the natural (not artificially manipulated) world: so whereas evolved minds could construct spatial frameworks and perform some trivial spatial inferences in a more or less tacit way by exploiting modules shaped by natural selection, how could one think exploiting explicit complicated geometrical concepts without having picked them up outside, after having produced them?

A mind consisting of different separated implicit templates of thinking and modes of inferences exemplified in various exemplars expressed through natural language cannot come up with certain mathematical and geometrical entities without the help of the external representations. The only way is to extend the mind into the material world, exploiting paper, blackboards, symbols, artificial languages, and other various semiotic tools, to provide semiotic anchors for finding ways of inferring that have no natural home within the mind, that is for finding ways of inferring and concepts that take us beyond those that natural selection and cultural training could enable us to possess at a certain moment.

Hence, we can hypothesize - for example - that many valid spatial reasoning habits which in human agents are performed internally have a deep origin in the past experience lived in the interplay with iconic systems at first represented in the environment. As I have just illustrated other recorded thinking habits only partially occur internally because they are hybridized with the exploitation of already available or suitably constructed external diagrammatic artifacts.

\subsection{Delegated and Intrinsic Constraints in External Agents}

We have said that through the cognitive interplay with external representations the human agent is able to pick up and use what suggested by the constraints and features intrinsic to their external materiality and to their relative established conventionality: artificial languages, proofs, examples, etc. Let us consider the example above (section 4.2 ) of the sum of the internal angles of a triangle. At the beginning the human agent - that is an interpretant in Peircian sense - embodies a sign in the external world that is in this case an icon endowed with "intentional" delegated cognitive conventional and public features - meanings - that resort to some already known properties of the Euclidean geometry: a certain language and a certain notation, the definition of a triangle, the properties of parallel lines that also hold in case of new elements and "auxiliary" constructions obtained through manipulation, etc. Then she looks, 
through diagram manipulations, for possible necessary consequences that occur over there, in the diagram/icon and that obey both

- the conventional delegated properties and

- the properties intrinsic to the materiality of the model.

This external model is a kind of autonomous cognitive agent offered to new interpretants of the problem/object in question. The model can be picked up later and acknowledged by the human agent through fixation of a new neural configuration - a new "thought" (in the case the new result concerning the sum of the internal angles).

The distinction above between delegated and intrinsic and immanent properties is also clear if we adopt the Peircian semiotic perspective. Peirce - speaking about the case of syllogistic logic, and not of geometry or algebra - deals with this problem by making an important distinction between what is going on in the brain of the logical human agent and the autonomous power of the chosen external system of representation or diagrammatization [23]. The presence of this "autonomous power" explains why I attribute to the system of representation a status of cognitive agency similar to the one of a human person, even if of course lacking aspects like direct intention and responsibility. Any diagram, Peirce says, makes use

[...] of a particular system of symbols - a perfectly regular and very limited kind of language. It may be a part of a logician's duty to show how ordinary ways of speaking and of thinking are to be translated into that symbolism of formal logic; but it is no part of syllogistic itself. Logical principles of inference are merely rules for the illative transformation of the symbols of the particular system employed. If the system is essentially changed, they will be quite different [52, 2.599].

Of course the argumentation above also holds for our case of iconic geometric representation. This distinction integrates the one I have introduced above in the two levels of representations, and in some sense blurs it by showing how the hybrid character of the system composed by the two levels themselves, where the whole package of sensorial and kinesthetic abilities are involved.

The construction of the diagram also depends on those delegated semiotic properties that are embedded in what Peirce calls "precept" as he says in the passage we have already quoted above and not only on the constraints expressed by the materiality of the model itself. ${ }^{23}$

Pickering [57] depicts the role of some externalities (representations, artifacts, tools, etc.) in terms of a kind of non-human agency that interactively stabilizes with human agency in a dialectic of resistance and accommodation [57, p. 17 and p. 22]. The two agencies, for example in scientific reasoning, originate a co-production of cognition the results of which cannot be presented and identified in advance: the outcome of the co-production is intrinsically "unpredictable". Latour's notions of the de-humanizing effect of technologies are based on the so-called "actor network theory", ${ }^{24}$ which also stresses the semiotic role of externalities like the so-called non human agents. The actor network theory basically maintains that we should think of science, technology,

\footnotetext{
${ }^{23}$ It is worth noting that this process is obviously completely related to the Peircian idea of pragmatism [24], that he simply considers "the experimental method" which is the procedure of all science.

${ }^{24}$ This theory has been proposed by Callon, Latour himself, and Law $[9,10,30,31,11,32]$.
} 


\section{Multimodal Abduction}

and society as a field of human and non-human (material) agency. Human and nonhuman agents are associated with one another in networks, and they evolve together within these networks. Because the two aspects are equally important, neither can be reduced to the other: "An actor network is simultaneously an actor whose activity is networking heterogeneous elements and a network that is able to redefine and transform what is it made of $[\ldots]$. The actor network is reducible neither to an actor alone nor to a network" [10, p. 93].

The operation on a diagram has reduced complexity enabling concentration on essential relations and has revealed new data. Moreover, through manipulations of the diagram new perspectives are offered to the observation, or interesting anomalies with respect the internal expectations are discovered. In the case of mathematicians, Peirce maintains, the diagram "puts before him an icon by the observation of which he detects relations between parts of the diagram other than those which were used in its construction" [54, III, p. 749]: "unnoticed and hidden relations among the parts" are discovered $[52,3.363]$. This activity is a kind of "thinking through doing": "In geometry, subsidiary lines are drawn. In algebra permissible transformations are made. Thereupon, the faculty of observation is called into play. [...] Theorematic reasoning invariably depends upon experimentation with individual schemata" [52, 4.233].

We have said that firstly the human agent embodies a sign in the external world that is in this geometrical case an icon endowed with "intentional" delegated cognitive conventional and public features - meanings - that resort to some already known properties of the Euclidean geometry: these features can be considered a kind of immanent rationality and regularity [24] that establishes a disciplinary field to envisage conclusions. ${ }^{25}$ The system remains relative to the chosen conventional framework. They are real as long as there is no serious doubt in their adequacy: "The 'real,' for Peirce, is part of an evolutionary process and while 'pragmatic belief' and unconscious habits might be doubled from a scientific point a view, such a science might also formulate serious doubts in its own representational systems" [24, p. 295].

Let us imagine we choose a different representational system still exploiting material and external diagrams. Through the manipulation of the new symbols and diagrams we expect very different conclusions. An example is the one of the nonEuclidean discoveries. In Euclidean geometry, by adopting the postulate of parallels we necessarily arrive to the ineluctable conclusion that the sum of internal angles of a triangle is $180^{\circ}$, but this does not occur in the case of the non-Euclidean geometry where a different selected representational system - that still uses Euclidean icons determines quite different possibilities of constructions, and thus different results from iconic experimenting. ${ }^{26}$

\footnotetext{
${ }^{25}$ Paavola, Hakkarainen, and Sintonen [51] consider the interplay between internal and external aspects of abductive reasoning in the framework of the interrogative model of the so-called "explanation-seeking why-questions". They emphasize the interaction with the "environment" and show the importance of the heuristic strategies and of their trialogic nature (inquirer and fellow inquirers, object of inquiry, mediating artefacts and processes), also taking advantage of Davidson's ideas concerning triangulation.

${ }^{26}$ I have illustrated this problem in detail in [?].
} 


\section{Conclusion}

The main thesis of this paper is that the process of externalization of mind is a significant cognitive perspective able to unveil some basic features of abductive reasoning. Its fertility in explaining the semiotic interplay between internal and external levels of cognition is evident. I maintain that various aspects of creative meaning formation could take advantage of the research on this interplay: for instance study on external mediators can provide a better understanding of the processes of explanation and discovery in science and in some areas of artificial intelligence related to mechanizing discovery processes. ${ }^{27}$

The cognitive referral to the central role of the relation between meaningful behaviour and dynamical interactions with the environment becomes critical to the problem of meaning formation. The perspectives above, resorting to the exploitation of a very interdisciplinary interplay will further shed light on how concrete manipulations of external objects influence the abductive generation of hypotheses and so on the characters of what I call manipulative abduction showing how we can find methods of constructivity - and their computational counterparts - in scientific and everyday reasoning based on external models and "epistemic mediators" [39].

Another interesting application is given in the area of chance discovery [43] and of mathematical diagrams [41]. Concrete manipulations of the external world constitute a fundamental passage in chance discovery: by a process of manipulative abduction it is possible to build semiotic prostheses that furnish a kind of embodied and unexpressed knowledge that holds a key role in the subsequent processes of scientific comprehension and discovery but also in ethical thinking and in moral deliberation. For example I have viewed moral reasoning as a form of "possible worlds" anticipation, a way of getting chances to shape the human world and act in it [38].

\section{References}

[1] A. Aliseda. Seeking Explanations: Abduction in Logic, Philosophy of Science and Artificial Intelligence. PhD thesis, Amsterdam: Institute for Logic, Language and Computation, 1997.

[2] A. Aliseda. Abductive Reasoning. Logical Investigations into Discovery and Explanation. Springer, Berlin, 2006.

[3] D. Batens. A diagrammatic proof search procedure as part of a formal approach to problem solving. In L. Magnani, editor, Model-Based Reasoning in Science and Engineering, pages 265-284, London, 2006. College Publications.

[4] C. Boutilier and V. Becher. Abduction as belief revision. Artificial Intelligence, 77:43-94, 1995.

[5] J. Brent. A brief introduction to the life and thought of charles sanders peirce. In J. Muller and J. Brent, editors, Peirce, Semiosis, and Psychoanalysis, pages 1-14. John Hopkins, Baltimore and London, 2000.

[6] S. Bringsjiord. Is (Gödelian) model-based deductive reasoning computational? Philosophica, 61:51-76, 2000. Special Issue Abduction and Scientific Discovery.

[7] R. A. Brooks. Intelligence without representation. Artificial Intelligence, 47:139-159, 1991.

[8] T. Bylander, D. Allemang, M. C. Tanner, and J. R. Josephson. The computational complexity of abduction. Artificial Intelligence, 49:25-60, 1991.

[9] M. Callon. Four models for the dynamics of science. In S. Jasanoff, G. E. Markle, J. C. Petersen, and T. J. Pinch, editors, Handbook of Science and Technology Studies, pages 29-63, Los Angeles, 1994. Sage.

${ }^{27}$ On the recent achievements in the area of the machine discovery simulations of model-based creative tasks cf $[42]$ 


\section{Multimodal Abduction}

[10] M. Callon. Society in the making: the study of technology as a tool for sociological analysis. In W. E. Bjiker, T. P. Hughes, and T. Pinch, editors, The Social Construction of Technological Systems, pages 83-106, Cambridge, MA, 1997. MIT Press.

[11] M. Callon and B. Latour. Don't throw the baby out with the bath school! a reply to collins and yearley. In A. Pickering, editor, Science as Practice and Culture, pages 343-368, Chicago and London, 1992. The University of Chicago Press.

[12] A. Clark. Natural-Born Cyborgs. Minds, Technologies, and the Future of Human Intelligence. Oxford University Press, Oxford, 2003.

[13] V. Colapietro. Futher consequences of a singular capacity. In J. Muller and J. Brent, editors, Peirce, Semiosis, and Psychoanalysis, pages 136-58. John Hopkins, Baltimore and London, 2000.

[14] A. Cornuéjols, A. Tiberghien, and G. Collet. A new mechanism for transfer between conceptual domains in scientific discovery and education. Foundations of Science, 5(2):129-155, 2000. Special Issue on 'Model-based Reasoning in Science: Learning and Discovery', ed. by L. Magnani and N. J. Nersessian and P. Thagard.

[15] P. Flach and A. Kakas, editors. Abductive and Inductive Reasoning: Essays on Their Relation and Integration, Dordrecht, 2000. Kluwer Academic Publishers.

[16] A. Gatti and L. Magnani. On the representational role of the environment and on the cognitive nature of manipulations. In L. Magnani, editor, Computing, Philosophy and Cognition, pages 227-242, London, 2006. King's College Pubblications.

[17] J. J. Gibson. The Ecological Approach to Visual Perception. Houghton Mifflin, Boston, MA, 1979.

[18] D. Gooding. Experiment and the Making of Meaning. Kluwer, Dordrecht, 1990.

[19] C. G. Hempel. Philosophy of Natural Science. Prentice-Hall, Englewood Cliffs, NJ, 1966.

[20] J. Hintikka. What is abduction? The fundamental problem of contemporary epistemology. Transactions of the Charles S. Peirce Society, 34:503-533, 1998.

[21] J. Hintikka and U. Remes. The Method of Analysis. Its Geometrical Origin and Its General Significance. Reidel, Dordrecht, 1974.

[22] M. H. G. Hoffmann. Problems with peirce's concept of abduction. Foundations of Science, 4(3):271-305, 1999.

[23] M. H. G. Hoffmann. Peirce's 'diagrammatic reasoning as a solution of the learning paradox. In G. Debrock, editor, Process Pragmatism: Essays on a Quiet Philosophical Revolution, pages 121-143. Rodopi Press, Amsterdam, 2003.

[24] M. H. G. Hoffmann. How to get it. diagrammatic reasoning as a tool for knowledge development and its pragmatic dimension. Foundations of Science, 9:285-305, 2004.

[25] E. Hutchins. Cognition in the Wild. MIT Press, Cambridge, MA, 1995.

[26] E. Hutchins. Cognitive artifacts. In R. A. Wilson and F. C. Keil, editors, Encyclopedia of the Cognitive Sciences, pages 126-7. The MIT Press, Cambridge, MA, 1999.

[27] P. N. Johnson-Laird. Mental Models. Harvard University Press, Cambridge, MA, 1983.

[28] I. Kant. Critique of Pure Reason. MacMillan, London, 1929. translated by N. Kemp Smith, originally published 1787, reprint 1998 .

[29] D. Kirsh and P. Maglio. On distinguishing epistemic from pragmatic action. Cognitive Science, 18:513-549, 1994.

[30] J. Latour. Science in Action: How to follow Scientists and Engineers through Society. Harvard University Press, Cambridge, MA, 1987.

[31] J. Latour. The Pasteurization of France. Harvard University Press, Cambridge, MA, 1988.

[32] J. Law. Modernity, Myth, and Materialism. Blackwell, Oxford, 1993.

[33] L. Magnani. Inconsistencies and creative abduction in science. In AI and Scientific Creativity. Proceedings of the AISB99 Symposium on Scientific Creativity, pages 1-8, Edinburgh, 1999. Society for the Study of Artificial Intelligence and Simulation of Behaviour, University of Edinburgh.

[34] L. Magnani. Semiotic brains and artificial minds. How brains make up material cognitive systems. In A. Loula, R. Gudwin, and J. Queiroz, editors, Semiotics and Intelligent Systems Development. Idea Group Inc., Hershey, PA, 2000. 
[35] L. Magnani. Abduction, Reason, and Science. Processes of Discovery and Explanation. Kluwer Academic/Plenum Publishers, New York, 2001.

[36] L. Magnani. Limitations of recent formal models of abductive reasoning. In A. Kakas and F. Toni, editors, Abductive Reasoning. KKR-2, 17th International Joint Conference on Artificial Intelligence (IJCAI 2001), pages 34-40, Berlin, 2001. Springer.

[37] L. Magnani. Philosophy and Geometry. Theoretical and Historical Issues. Kluwer Academic Publisher, Dordrecht, 2001.

[38] L. Magnani. Moral mediators. prefiguring ethical chances in a human world. In H. Shoji and Y. Matsuo, editors, Proceedings of the 3rd International Workshop on Chance Discovery, pages 1-20, Crete, Greece, 2003. Cognitive Science Society. HCI International Conference, June 2003.

[39] L. Magnani. Conjectures and manipulations. computational modeling and the extra-theoretical dimension of scientific discovery. Minds and Machines, 14:507-537, 2004.

[40] L. Magnani. Mimetic minds. meaning formation through epistemic mediators and external representations. In A. Loula, R. Gudwin, and J. Queiroz, editors, Artificial Cognition Systems, pages 327-357. Idea Group Publishers, Hershey, PA, 2006.

[41] L. Magnani and R. Dossena. Perceiving the infinite and the infinitesimal world: unveiling and optical diagrams and the construction of mathematical concepts. Foundations of Science, 10:723, 2005.

[42] L. Magnani, N.J. Nersessian, and C. Pizzi, editors. Logical and Computational Aspects of ModelBased Reasoning, Dordrecht, 2002. Kluwer Academic Publishers.

[43] L. Magnani, M. Piazza, and R. Dossena. Epistemic mediators and chance morphodynamics. In A. Abe, editor, Proceedings of PRICAI-02 Conference, Working Notes of the 2nd International Workshop on Chance Discovery, pages 38-46, Tokyo, 2002.

[44] J. Meheus. Model-based reasoning in creative processes. In L. Magnani, N.J. Nersessian, and P. Thagard, editors, Model Based Reasoning in Scientific Discovery, pages 199-217, New York, 1999. Plenum Publishers/Kluwer Academic.

[45] J. Meheus and D. Batens. A formal logic for abductive reasoning. Logic Journal of the IGPL, 14(1):221-236, 2006.

[46] J. Meheus, L. Verhoeven, M. Van Dyck, and D. Provijn. Ampliative adaptive logics and the foundation of logic-based approaches to abduction. In L. Magnani, N. J. Nersessian, and C. Pizzi, editors, Logical and computational aspects of model based reas, pages 39-71, Dordrecht, 2002. Kluwer Academic Publishers.

[47] N. Monekosso, P. Remagnino, and F. J. Ferri. Learning machines for chance discovery. In A. Abe and R. Oehlmann, editors, Workshop 4: The 1st European Workshop on Chance Discovery, pages 84-93. Valencia, Spain, 2004.

[48] N. J. Nersessian. Should physicists preach what they practice? Constructive modeling in doing and learning physics. Science and Education, 4:203-226, 1995.

[49] N. J. Nersessian. Model-based reasoning in conceptual change. In L. Magnani, N. J. Nersessian, and P. Thagard, editors, Model-based Reasoning in Scientific Discovery, pages 5-22, New York, 1999. Kluwer Academic/Plenum Publishers.

[50] I. Niiniluoto. Abduction and geometrical analysis. notes on Charles S. Peirce and Edgar Allan Poe. In L. Magnani, N. J. Nersessian, and P. Thagard, editors, Model Based Reasoning in Scientific Discovery, pages 239-254, New York, 1999. Plenum Publishers/Kluwer Academic.

[51] S. Paavola, K. Hakkarainen, and M. Sintonen. Abduction with dialogical and trialogical means. Logic Journal of the IGPL, 14(1):137-150, 2006.

[52] C. S. Peirce. Collected Papers of Charles Sanders Peirce. Harvard University Press, Cambridge, MA, 1931-1958. vols. 1-6, Hartshorne, C. and Weiss, P., eds.; vols. 7-8, Burks, A. W., ed.

[53] C. S. Peirce. The Charles S. Peirce Papers: Manuscript Collection in the Houghton Library. The University of Massachusetts Press, Worcester, MA, 1967. Annotated Catalogue of the Papers of Charles S. Peirce. Numbered according to Richard S. Robin. Available in the Peirce Microfilm edition. Pagination: CSP $=$ Peirce / ISP $=$ Institute for Studies in Pragmaticism.

[54] C. S. Peirce. The New Elements of Mathematics by Charles Sanders Peirce. Mouton/Humanities Press, The Hague-Paris/Atlantic Higlands, NJ, 1976. vols I-IV, edited by C. Eisele.

[55] C. S. Peirce. Historical Perspectives on Peirce's Logic of Science: A History of Science. Mouton, Berlin, 1987. vols. I-II, edited by C. Eisele. 


\section{Multimodal Abduction}

[56] J. Piaget. Adaption and Intelligence. University of Chicago Press, Chicago, 1974.

[57] A. Pickering. The Mangle of Practice. Time, Agency, and Science. The University of Chicago Press, Chicago and London, 1995.

[58] S. Pinker. Language as an adaptation to the cognitive niche. In M. H. Christiansen and S. Kirby, editors, Language Evolution: The States of the Art. Oxford University Press, 2003.

[59] K. R. Popper. The Logic of Scientific Discovery. Hutchinson, London, New York, 1959.

[60] J. Queiroz and F. Merrell, editors. Abduction: Between Subjectivity and Objectivity, volume 153. 2005. Special Issue of the Journal Semiotica.

[61] M. Ramoni, M. Stefanelli, L. Magnani, and G. Barosi. An epistemological framework for medical knowledge-based systems. IEEE Transactions on Systems, Man, and Cybernetics, 22(6):1361$1375,1992$.

[62] P. Thagard. Conceptual Revolutions. Princeton University Press, Princeton, 1992.

[63] P. Thagard. How does the brain form hypotheses? Towards a neurologically realistic computational model of explanation. In P. Thagard, P. Langley, L. Magnani, and C. Shunn, editors, Symposium "Generating explanatory hypotheses: mind, computer, brain, and world", Stresa, Italy, 2005. Cognitive Science Society, CD-Rom. Proceedings of the 27th International Cognitive Science Conference.

[64] P. Thagard. Abductive inference: from philosophical analysis to neural mechanisms. In A. Feeney and E. Heit, editors, Inductive Reasoning: Cognitive, Mathematical, and Neuroscientific Approaches, Cambridge, 2006. Cambridge University Press. Forthcoming.

[65] P. Thagard and C. P. Shelley. Abductive reasoning: logic, visual thinking, and coherence. In M. L. Dalla Chiara, K. Doets, D. Mundici, and J. van Benthem, editors, Logic and Scientific Methods, pages 413-427, Dordrecht, 1997. Kluwer.

[66] H. J. Thomas. Are theories of imagery theories of imagination? an active perception ap-proach to conscious mental content. Cognitive Science, 23(2):207-245, 1999.

[67] J. Woods. The Death of Argument. Kluwer Academic Publishers, Dordrecht, 2004.

[68] J. Zhang. The nature of external representations in problem solving. Cognitive Science, 21(2):179-217, 1997

Received March 31, 2006 